\title{
Air Quality Action Plans in the UK: an overview and evaluation of process and practice
}

\author{
C. I. Beattie, T. J. Chatterton, E. Hayes, N. Leksmono, \\ J. W. S. Longhurst \& N. K. Woodfield \\ Air Quality Research Group, Faculty of Applied Sciences, \\ University of the West of England, Frenchay Campus, Bristol, UK
}

\begin{abstract}
Local Air Quality Management is an effects-based process by which local authorities are required to review and assess their local air quality in relation to health-based air quality objectives. Where it is predicted that objectives will not be met and members of the public are exposed to elevated levels of pollutants, authorities are required to declare Air Quality Management Areas (AQMAs) and subsequently develop and implement Air Quality Action Plans (AQAPs) to improve air quality to acceptable levels. The majority of AQMAs $(>90 \%)$ are predominantly transport related, and as such Local Transport Plans (LTPs) will be critical to the successful implementation of measures to improve air quality. LTPs are currently moving into the second round of a 5-year cycle of planning, with Plans being submitted to Government in July 2005 to cover the 2006-2011 period. In order to align AQAP and LTP more closely, and to reduce the number of policies and plans required of councils, local authorities with air quality problems arising from transport emissions have the freedom to include AQAPs within their LTP. LTP's now include air quality as one of the four priorities. This move to integrate the two processes is seen largely as positive, but it is still unknown how the two processes (which still work to different timescales and report to different government departments) will be implemented in practice. This paper will provide an overview of the air quality action planning and local transport planning processes and then review three case study local authorities to examine the practice of air quality action planning in the context of air quality, organisational and political challenges.

Keywords: Air Quality Action Plan, Local Transport Plan, Air Quality Management.
\end{abstract}




\section{Introduction to Local Air Quality Management}

The Air Quality Management (AQM) framework in the UK is designed to be an effects-based solution to air pollutants currently affecting human health [1]. The AQM process has been legislated through the Environment Act 1995, which required a National Air Quality Strategy [2] to be published. This has since been revised [3] to reflect developments in European legislation, technological and scientific advances, improved air pollution modelling techniques and an increasingly better understanding of the economic and social issues involved. The Air Quality Strategy is currently undergoing a further revision due for consultation in 2005. All versions of the Air Quality Strategy are underpinned by the same precautionary, risk management based principles. These are based on the setting of health-based standards and objectives for eight pollutants, seven of which are managed partly at the local scale. The eighth, ozone, has much wider regional effects and is therefore being tackled only through national and international intervention (although it is acknowledged that independent local actions reducing NOx or VOC precursors may have beneficial effects). The primary responsibility of local authorities is to undertake a review and assessment of air quality within their locality. These assessments are undertaken at regular intervals and consist of 'screening' assessments and more rigorous 'detailed assessments' where an objective is deemed at risk. Following a Detailed Assessment, where air quality objectives are not likely to be met at a future target date, Air Quality Management Areas (AQMAs) must be designated and an Air Quality Action Plan (AQAP) put in place to improve the situation in these 'hot-spot' locations. Currently nearly a third of local authorities in Great Britain has AQMAs and therefore has the requirement to develop and implement AQAPs (www.airquality.co.uk for details).

The variety of sources of air pollution means that, if the AQM process is to succeed in the long term, solutions to identified problems will be required from transport, land-use and economic planning sectors of local government in liaison with various other agencies, regulators and outside bodies. As such the task is inherently multi-disciplinary and an integrated, collaborative approach will be necessary. The approaches required will depend on the stages of the AQM process. The review and assessment phase was largely undertaken by environmental health professionals with information requirements typically from transport planning professionals (regarding local traffic data), Highways Agency (responsible for motorways and trunk roads) and the Environment Agency (regulators of larger industrial processes). As the process moves on from the descriptive and analytical phase of defining the scope and scale of the problem to action planning (or the implementation of non-mandatory local authority local air quality strategies), a far more inclusive approach is required, which will not necessarily be led by environmental health professionals. Planners in the widest sense of the description will need to encompass air quality considerations within their own decision-making processes. This constitutes a fundamental cultural change in the local authorities approach to managing local air quality and a 
significant step change in the process of LAQM where problem definition is superseded by solution identification and implementation.

\section{Introduction to Local Transport Planning}

A Local Transport Plan (LTP) sets out a five-year strategy for the development of local and integrated transport. LTPs were first introduced in the 1998 Transport White Paper on an integrated transport policy 'A New Deal for Transport: Better for Everyone' [4] and became a statutory requirement for local transport authorities in England, outside London, under the Transport Act 2000 [5]. LTPs also include bids for funding from central Government to enable the implementation of local transport schemes. In addition to an LTP, there is a requirement to produce Annual Progress Reports to show the progress made in implementing the LTP and to report the changes that have occurred.

With the advent of LTPs in 2000, transport planning in the UK underwent a rapid transition [6]. The principle elements of the new approach focused less on the reliance on road construction (i.e. predict and provide), instead more focus is directed at the adoption of a package of solutions to given problems and in general terms managing travel demand rather than providing for it. The second 'round' of LTPs (LTP2) are due to be submitted in July 2005 (these will be regarded as provisional with authorities having the opportunity to produce revised and finalised LTPs by the end of March 2006). This round of LTPs will focus efforts on four key priorities; air quality, congestion, accessibility and road safety.

There is a separate arrangement for local authorities rated as 'excellent' under Comprehensive Performance Assessment. Such local authorities are exempt from the requirement to produce seven statutory plans, including AQAPs and LTPs, though can choose to do so voluntarily [7]. Such authorities still have a statutory duty to work towards meeting the air quality objectives and therefore production of the Plans may be valuable as a mechanism for doing so.

Recently published guidance on LTPs [8] also endorsed the integration of AQAPs and LTPs to enable air quality problems to be dealt with in a holistic manner. More importantly it encourages greater collaboration between environmental health officers and transport planners. This guidance mirrors that provided by the Department for Environment, Food and Rural Affairs (Defra) in an Addendum to their LAQM Policy Guidance [9].

However, despite this policy framework, latest data show that road traffic continues to rise [10]. The first Department for Transport (DfT) progress report on the UK 10-year Transport Plan, published in December 2002, acknowledged that to reduce congestion in England to below 2000 levels by 2010 would be unachievable. New data indicate that traffic is forecast to rise by between 20 and $25 \%$ over the 10 year period, while congestion will rise by between 11 and $20 \%$. Despite the apparent rejection of 'predict and provide' towards the management of travel demand in the Integrated Transport White Paper, DfT is also investing $£ 21$ billion over 10 years to improve the trunk road network and increase overall capacity. Although this investment is mirrored by a large increase in investment 
in public transport, particularly rail, these new roads are likely to generate additional traffic, an approach which appears to contradict the philosophy set out in the Integrated Transport White Paper [10].

\section{Integration of air quality and transport planning: case studies}

The problem of ever-increasing traffic volumes, experienced in many countries, is symptomatic of a more dispersed society [10] where land-use planning policy has allowed both residential and occupational development in out-of-town locations, resulting in people needing to travel further to work. With increasing car ownership, rising urban populations and a greater reliance on private vehicles, escalating number of vehicles on the roads pose a significant threat to local air quality. Over $80 \%$ of journeys (by distance travelled) are made by car in Great Britain. This demonstrates a clear need for national and local policy to address the increasing reliance on the car as the primary mode of transport.

The difficulty for central and local governments is to balance public expectations of personal mobility and accessibility with a clean atmosphere that poses no significant risk to public health [11]. However, national policy measures have struggled to address the air quality consequences of the growth in vehicle numbers and distance travelled. The policy challenge is illustrated by the scale of growth in the number of cars registered in the UK, which increased by $63 \%$ from $19.2 \mathrm{~m}$ to $31.2 \mathrm{~m}$ between 1980 and 2003 [12]. It is not only overall vehicle emissions that are causing a problem. Traffic congestion poses a great threat to local air quality, which may require politically contentious measures such as congestion charging, or other demand management mechanisms, to bring about reduced congestion.

In order to align AQAPs and LTPs more closely, and to reduce the number of policies and plans, the Local Government White Paper (paragraph 4.30) [13] states 'Her Majesty's Government will no longer require the production of a separate air quality management action plan where an air quality problem arises because of transport pollution. Instead, councils will be free to address this through their Local Transport Plan.'

To illustrate how this process is occurring in practice the paper will describe how three local authorities are attempting to integrate their air quality action plans into the Local Transport Planning process. The authors of this paper have experience of all three case study authorities, having worked with all of them in some capacity. As such, they are presented as individual examples, rather than being representative of all authorities in the UK. It should be recognised that the integration of AQAPs and LTPs is still at an early stage in the process and as such this paper focuses on outlining recommendations rather than producing a full analysis of the outcomes of local efforts to integrate air quality and transport planning processes.

\subsection{Leicester City Council}

Leicester City Council (LCC), situated in the East Midlands of England is a unitary authority (i.e. one-tier authority responsible for transport planning as well 
as environmental protection) but is surrounded by a two-tier structure whereby the County is responsible for transport planning and the district councils are responsible for pollution control. As such, LCC transport planners work closely with Leicestershire County Council transport planners, and likewise, the pollution control officers of both LCC and the other districts work closely with each other. LCC has declared an Air Quality Management Area (AQMA) for nitrogen dioxide (with regard to the annual mean objective) within an area covering central Leicester, including the main road radial routes into Leicester. Two of Leicester's neighbouring authorities also have AQMAs on arterial routes into Leicester.

As a unitary authority, LCC is the lead authority for producing the jointly submitted Central Leicestershire Package area LTP, a document produced in partnership with the County Council, covering the City and the surrounding contiguous urban areas of Leicestershire. LCC has always been seen as innovative in terms of transport policy [14]. Even before Government guidance, LCC (then the highway authority for both Leicester City and County) recognised the importance of locating new development where it could be served by improved public services, as well as the need for improvements to public transport and better integration of land-use and transport planning. In essence, the policy strategy aimed to widen transport choice, manage demand and consider transport planning in an integrated fashion.

As transport planning processes developed in Leicester and Leicestershire, the air quality management process also progressed alongside them. Once their AQMA had been declared, and the council was due to commence action planning, LCC employed academic consultants to provide an impartial and objective (i.e. non-council) perspective and bring together transport planners (city and County), land-use planners and others involved in sustainability and other aspects of Council work. An all-day workshop was held in Leicester, which highlighted the need for action to those involved, and also the need to work together. The workshop took the format of working in small groups to look at what options LCC had for improving air quality, a brief evaluation of those options (in terms of how they would improve air quality, how they would impact on policies already in place within LCC, what wider economic, social and environmental impacts they might have). It concluded with an indicative prioritisation of the options which the day had highlighted. From here a small working group developed the action plan, in consultation with local transport planners which will be integrated into LTP2.

\subsection{Newcastle City Council}

Newcastle City Council (NCC) is located in the North East of England and is a Metropolitan Borough Council, but transport planning is undertaken on an areawide (Tyne and Wear) basis. Therefore air quality action plans and Local Transport Plans are undertaken at different levels of local government organisation providing further challenges for co-ordination. The timing of NCC declaring an AQMA fitted in well with the LTP process, in that their action plan needed to be produced in the same year as the LTP2 document needed to be 
developed. Because of the need to include air quality considerations in the LTP, transport planners were keen to engage with pollution control specialists. In order to ease the integration of the two processes, external academic consultants were employed to help co-ordinate the action planning process, run events to involve transport planners and planners, and also to assist the all the local authorities within the Tyne and Wear area in developing a joint Air Quality Strategy. The two processes of transport planning and LAQM have developed together and although a separate AQAP report will be produced, this will be fully integrated into the LTP process by transport planners extracting what is required and referencing the full document.

In terms of communication and co-operation, the process has worked very effectively, with both sides of the partnership gaining both expertise and knowledge from the other. Because the LTP is developed at a Tyne and Wear spatial level, the four surrounding authorities have been involved in the process which has proved extremely useful for Newcastle's action plan. As the scientific assessment element of LAQM has progressed, three of the other Tyne and Wear authorities have found the need to declare AQMAs in their areas due to transport emissions. Having transport planners 'on board' from an early stage will certainly assist in the effective integration of the resultant future AQAPs into the LTP process.

\subsection{Bristol City Council and former Avon authorities}

Bristol City Council (BCC) is a unitary (one-tier) authority, and is one of four local authorities that constitute a former county known as the County of Avon. As such, BCC has both transport planning and pollution control responsibilities. $\mathrm{BCC}$ has long had a very good working relationship between transport planners and pollution control officers and this has been recognised by central Government in awarding them with the designation 'Centre of Excellence' in transport planning with regard to their air quality work. Close collaboration between departments, through frequent and regular meetings, has resulted in a more effective and integrated AQAP. The action planning process has been led by transport planners, and consequently a greater understanding of the process of air quality management has been fostered across the council. BCC developed their AQAP midway through the LTP cycle, which led to problems with funding for the proposed measures. Bristol's action plan contains 27 measures which are designed to 'top-up' the existing LTP. Proposals range from 'soft' measures like travel plans and car clubs through to emissions reduction measures aimed at cleaning up vehicles. It also contains innovative measures such as a scrappage scheme to take the most polluting vehicles off the road and a low emission zone. Both will require feasibility work and consultation, but modelling has shown that if older cars were taken off the roads there would no longer be an air quality issue. DfT, the Government department responsible for local transport funding would not provide extra funds purely for air quality measures through the annual progress reporting process. However, Defra, the government department responsible for LAQM would also not provide funding, stating that AQAPs (related to transport) should be supported through the LTP process. The cost of 
the plan implementation has been estimated at approximately $£ 1$ million per year over a five year period. This level of funding cannot be found locally, and officers within BCC are pessimistic about funding the whole AQAP through the LTP2 process. The Council is currently consulting on local priorities, including the levels of funding which residents would like to see the council bid to central Government for. It is agreed by both transport planners and environmental health professionals that the maximum level of funding will be required in order to achieve the air quality objectives by the end of the LTP period.

\section{Discussion}

This paper has examined the issues surrounding the implementation of air quality action plans in the UK in relation to traffic related sources, and the integration of Local Transport Plans for improvements in air quality. The case studies have been taken from both one-tier (unitary) areas such as Bristol, as well as local authorities working within two-tier structures of government. The evaluation of the action planning process [15] has indicated that one of the major constraints on action planning is that local authorities do not have the appropriate powers of authority with respect to the implementation of targeted measures on identified emissions sources within their AQMA. Engagement with County Councils, as well as the Highways Agency who are responsible for trunk Roads and Motorways, has been problematic, with County Councils in some cases, providing little response or feedback on measures to improve air quality along sections of road under their control. Newcastle has managed to overcome this potential constraint through effective communication with transport planners at the Tyne and Wear level through their air quality steering group. This group involves all the metropolitan borough councils in Tyne and Wear, and so regional issues are also discussed, for example the issue of traffic management measures relating to commuters travelling into the area from the surrounding local authorities.

Whilst there have been strong trends towards integration at the local level, central governmental transport and environment departments have been through a number of re-organisations over the last decade. Recognising the problems of increasing car use, and acknowledging the interrelationship between transport, planning, economic development and the environment, the newly elected labour Government created the Department of Transport and the Regions (DETR) in 1997. Despite being created to facilitate joined-up decision making, DETR was split up in June 2001, with transport policy falling within the Department of Transport, Local Government and the Regional (DTLR) and environment falling within the Department for Environment, Food and Rural Affairs (DEFRA). Following the resignation of the Secretary of State for Transport, DTLR was itself split into the Department for Transport and the Office of the Deputy Prime Minister in May 2002. The former DETR ministry is now split across 3 ministries, which makes integration of the processes of transport planning, planning policy and environmental protection at a central government level, more time consuming and less effective. 
One of the perennial problems with implementing air quality action plans has always been how to fund them. In the Government's view, Local Transport Plans provide the main channel for funding improvements in air quality, however, there is no ring-fenced money available for air quality improvements with different priorities competing for limited resources. Another issue highlighted by the evaluation of action planning [15] was that the phasing of many action plans are out of step with the LTP process which has caused delays in attaining funding for measures, and in many cases it has meant that the action plan has been prepared without firm timescales for implementation. This has been a major issue in Bristol, but less so in Leicester or Newcastle, largely due to the timing of their AQMA declarations - a matter more due to fortune than something which can be planned for. However, even where the two processes coincide, it is by no means certain that measures identified and prioritised through an AQAP will be funded.

A further problem in linking AQAPs with Local Transport Plans is that LTPs can only cover some of the potential issues that need to be addressed. Air quality problems associated with motorway or trunk road traffic, or those associated with domestic or industrial emissions, have no specific funding attached to them. Longer term solutions implemented through the planning process are also unlikely to be included in an LTP framework. Through extensive work with local authorities in implementing both LAQM and the air quality aspects of LTPs, the authors consider that integrating AQAPs and LTPs is a positive move forward. It has raised the profile of air quality considerations within local councils and encouraged solutions to be integrated into arenas whereby they may, potentially, be implemented through central Government funding. However, local authorities are also struggling with other funding problems. The Energy Savings Trust (which provided funding for subsidising low emissions technology) has been cut leaving some councils, for example, unable to fund retrofitting of buses, preventing the tackling of a problem that in some cases has been identified a major contributor to local emissions and the cause of an AQMA.

\section{Conclusions and recommendations}

The case study authorities described in this paper provide evidence of increasing integration between transport and air quality planning. However, they also highlight the different priorities that will impact on the likely effectiveness of different plans and the recognition that funding air quality initiatives is difficult. The added complexity of the new process of integrating AQAPs and LTPs, particularly where multiple sources contribute to the air quality objective exceedence may be problematic. Where LTPs and LAQM are being integrated at different levels of local government, this also has the potential for conflict between the two processes. The case studies show that this can be overcome through early dialogue, either through specific steering groups, or through workshops aimed at wider audiences. It is recommended that through the sharing of best practice and by encouraging collaboration through mechanisms 
described above, or through sharing expertise in other ways (such as staff secondments between authorities or departments) air quality can attain a much higher profile within LTPs.

The relatively new requirement for Strategic Environmental Assessment (SEA) of Plans and Programmes may become an additional useful mechanism for integration. SEA is a process to ensure that environmental effects arising from proposed plans and programmes are identified, assessed, mitigated, communicated to decision-makers, monitored and that opportunities for public involvement are provided. LTPs have a requirement for an SEA which also provides a means by which air quality can be considered within wider planning policy. The effectiveness of the integration of LTPs and AQAPs in improving air quality can only be assessed over the 5 year period of LTP2. It is recommended therefore that more evaluatory research is undertaken comparing those local authorities with fully integrated AQAP and LTPs and those without.

\section{Acknowledgement}

The authors would like to thank the local authorities involved in this study, for their participation and for access to and use of use of the material included in this paper.

\section{References}

[1] Beattie, C.I., Longhurst, J.W.S., \& Woodfield, N.K. (2001) Air quality management: evolution of policy and practice in the UK as exemplified by the experience of English local government. Atmospheric Environment, 35, 1479-1490.

[2] Department of the Environment, Scottish Office, \& Welsh Office (1997) The United Kingdom National Air Quality Strategy. CM3587, The Stationary Office, London.

[3] Department of the Environment, Transport and the Regions, Scottish Executive, National Assembly for Wales, \& Department of the Environment for Northern Ireland (2000) The Air Quality Strategy for England, Scotland, Wales and Northern Ireland - Working Together for Clean Air. CM 4548, The Stationary Office, London.

[4] Department for Transport (1998). A New Deal for Transport: Better for Everyone. http://www.dft.gov.uk/stellent/groups/dft_about/documents/ pdf/dft_about_pdf_021588.pdf.

[5] HM Government (2000) Transport Act 2000. Statutory Instruments 2000 No. 38, The Stationery Office, London.

[6] Beattie, C.I., Longhurst, J.W.S., Simmons, A., \& Woodfield, N.K. (1999) Implementation of air quality management in urban areas of England - the role of transport planning. Urban Transport V Urban Transport and the Environment for the 21st Century (ed. by Sucharov L.), pp. 51-60. WIT Press, Southampton and Boston. 
[7] HM Government (2000) Local Government Act 2000. Statutory Instruments 2000 No. 22, The Stationery Office, London.

[8] Department for Transport (2004). Full Guidance on Local Transport Plans: Second $\quad$ Edition. http:/www.dft.gov.uk/stellent /groups/dft_localtrans/documents/pdf/dft_localtrans_pdf_504005.pdf.

[9] Defra (2005) Part IV of the Environment Act 1995. Local Air Quality Management. Policy Guidance: Addendum LAQM.PGA(05), Department for Environment, Food and Rural Affairs.

[10] Begg, D. \& Gray, D. (2004) Transport policy and vehicle emission objectives in the UK: is the marriage between transport and environmental policy over? Environmental Science and Policy, 7, 155-163.

[11] Longhurst, J.W.S. (1996) Transport and local air quality management in the UK. Urban Transport and the Environment II (ed. by J. M. Baldasano \& L. Sucharov), pp. 97-106. WIT Press, Southampton.

[12] Department for Transport (2004). Transport Trends: 2004 Edition. http:/www.dft.gov.uk/stellent/groups/dft_transstats/documents/pdf/dft_tra nsstats_pdf_508294.pdf.

[13] Office of the Deputy Prime Minister (2001) Local Government White Paper Strong Local Leadership - Quality Public Services: part I. http://www.odpm.gov.uk/stellent/groups/odpm_localgov/documents/pdf/o dpm_locgov_pdf_605685.pdf.

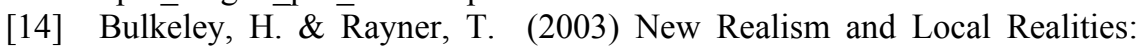
Local Transport Planning in Leicester and Cambridgeshire. Urban Studies, 40, 35-55.

[15] Maggs, R. \& Moorcroft, S. Evaluation of Local Authority Air Quality Action Planning through Local Air Quality Management. CS/AQ/AD102126/RM/2131 (Final). 2004. Report to Defra and the Devolved administrations. Casella Stanger, London. 